See discussions, stats, and author profiles for this publication at: https://www.researchgate.net/publication/312345750

\title{
Edible energy: balancing inputs and waste in food supply chain and biofuels from algae
}

Article in European Physical Journal Plus · January 2017

Dol: 10.1140/epjp/i2017-11301-8

CITATIONS

6 authors, including:

Gianluca Alimonti

INFN Istituto Nazionale di Fisica Nucleare, Milano, Italy

1,015 PUBLICATIONS 31,350 CITATIONS

SEE PROFILE

(2)

Rosaria Erika Pileci

Paul Scherrer Institut

6 PUBLICATIONS 10 CITATIONS

SEE PROFILE

Some of the authors of this publication are also working on these related projects:

Project ATLAS-Collaboration View project

Project

ATLAS Experiment View project
571

Riccardo Brambilla

University of Milan

2 PUBLICATIONS OCITATIONS

SEE PROFILE

(-) Francesca Rosa

ETH Zurich

2 PUBLICATIONS OCITATIONS

SEE PROFILE 


\title{
Edible energy: balancing inputs and waste in food supply chain and biofuels from algae
}

\author{
Gianluca Alimonti ${ }^{1,2, a}$, Riccardo Brambilla ${ }^{2, b}$, Rosaria Pileci $^{2, \mathrm{c}}$, Riccardo Romano ${ }^{2, \mathrm{~d}}$, Francesca Rosa ${ }^{3, \mathrm{e}}$, and \\ Luca Spinicci ${ }^{2, f}$ \\ 1 INFN, Milan, Italy \\ 2 Università degli Studi di Milano, Milan, Italy \\ 3 Università degli Studi di Milano-Bicocca, Milan, Italy
}

Received: 2 December 2016

Published online: 16 January 2017 - (C) Società Italiana di Fisica / Springer-Verlag 2017

\begin{abstract}
Energy is life. Without it there is no water, there is no nutrition. Man's ability to live, grow, produce wealth is closely linked to the energy availability and use. Fire has been the first energy conversion technology; since that moment, the link between energy and progress has been indissoluble. Nowadays, a much greater energy input into the food supply chain has made a much higher food production possible. This might have an impact on the water availability. Algae are a promising solution for the energy-foodwater nexus.
\end{abstract}

\section{Introduction}

About 10000 years ago, from 1 calorie spent as muscular work to obtain food products, Neolithic man gained 15 to 40 calories in nutritional value, depending on the product and on climatic conditions; to feed one person a few hectares of fertile soil had to be exploited on average [1]. Today the world average is about 0.2 hectares per person.

Only the supply of greater energy flows, both directly as fuel or electricity and indirectly in the form of chemicals or agricultural machinery, has enabled a simultaneous world population growth and an increase in average food availability per capita. This is bringing the attention to another important resource of our planet that is at the base of the food chain: water. Over two-thirds of the planet is covered by water but only about $2.5 \%$ is fresh water: $70 \%$ of annual freshwater withdrawals is used for agriculture, $20 \%$ for domestic or industrial use, $10 \%$ for energy. In fact, $70 \%$ of the fresh water we use, is used to feed the planet.

In the first section of this paper the energy inputs in the food supply chain are analized with emphasis on transportation, storage and packaging and an evaluation of the energy gain is presented. In the second section, energy losses in the food supply chain are presented together with an evaluation of possible recoveries. Energy production from cereal residue, presented in the following section, is one way to recover energy from agriculture: after an introduction about the world energy production from biomass, an assessment on the possible extraction of energy from the secondary products of cereals is presented. Finally some features of algae are highlighted: seaweeds may give an important contribution both to the energy production chain, having biofuels as possible output, and to the food supply chain, being used in human and animal nutrition. Algae may represent a potential in solving the energy-water-food nexus.

\footnotetext{
* Contribution to the Focus Point on "Plants for food, energy and sustainability" edited by G. Alimonti, S. Johansson, L. Mariani.

a e-mail: gianluca.alimonti@mi.infn.it

b e-mail: r.brambilla11@gmail.com

c e-mail: rosariaerika.pileci@gmail.com

d e-mail: riccardo.romano@studenti.unimi.it

e e-mail: francerosa@gmail.com

f e-mail: luca.spinicci@studenti.unimi.it
} 


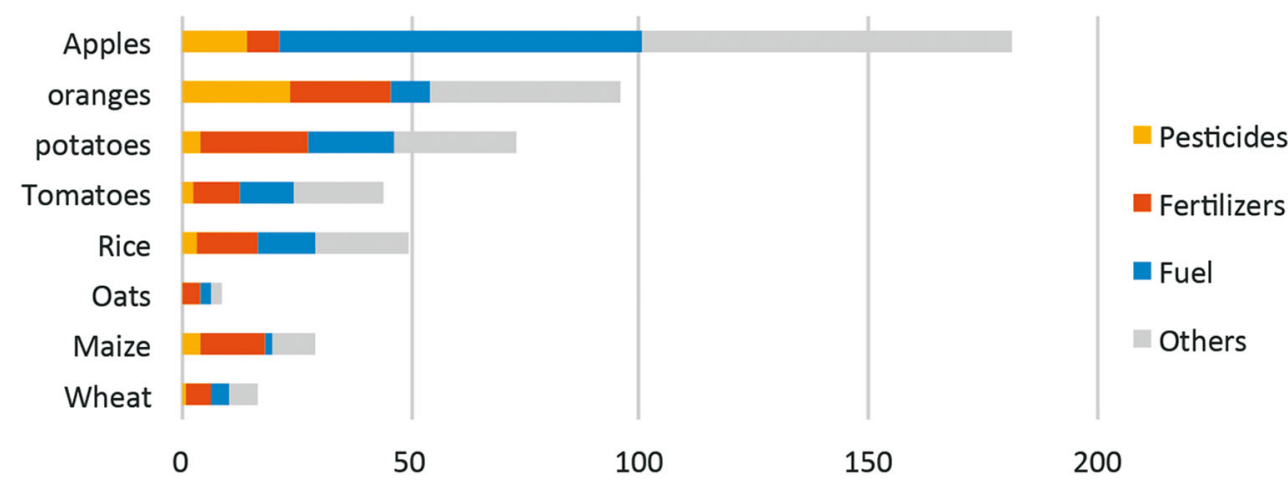

Fig. 1. Energy consumption for 1 ha crops [GJ/ha]. The energy consumption for pesticides, fertilizers and fuel is shown singularly; the remaining energy inputs for agricultural production are grouped. Adapted from [2-8].

\section{Energy in the food production chain}

In the last century, population growth pushed to improve food productivity: improved plant varieties, fertilizers, pesticides and other technical agricultural means allowed a very considerable increase of agricultural production. The ability to feed a greater number of people is related to an acquired higher productivity per hectare and to the capability to store food. The analysis of energy inputs in the food processing chain and its development in the last century is not easy given the several and complex steps that may affect the overall energy efficiency: data from agricultural production, processing, packaging and transportation have to be treated. For meat production, livestock breeding and slaughter have also to be considered. Most of the presented data are relative to Italy or United States.

\subsection{Agricultural production}

Agricultural productivity (energy output) can be increased either enhancing energy inputs or improving transformation efficiency; actually the first solution has allowed the productivity growth of the last century and in some cases a decrease of energy gain (energy output/energy input) has been observed [2]. Energy gain is one of the good indicators that show from an energy point of view how agriculture has changed in the twentieth century [9].

The usage of fertilizers, pesticides, and the increase of agricultural mechanization are the main elements that have allowed the increase in crops productivity in this last century: these are the most relevant energy-consuming elements within agricultural production. As summarized in fig. 1, in which these three elements are highlighted for different types of crops.

Fertilizers extracted from mineral deposits or artificially synthesized, show a worldwide almost fivefold increment from 1961 [10]. Fertilizers containing nitrogen, potassium and phosphate are used to supplement the natural soil nutrient supply and to build up soil fertility in order to satisfy the demand of crops with a high yield potential, in particular to compensate for the nutrients exported by the harvested products or lost by unavoidable leakages to the environment. The use of these fertilizers facilitates protein synthesis, increases the amount of chlorophyll in the leaves, eases the absorption of water and increases resistance to cold and pests. Energy inputs for production, packaging and application for these three kinds of fertilizer are taken from [3].

Pesticides are classified depending on their function: insecticides, fungicides, herbicides. Getting the amount of fertilizers and pesticides used in agriculture from [10] and the energy spent to produce and use them from [4,5], the energy needed for the process can be inferred.

Fuel consumption is closely linked to agricultural mechanization; it is thus possible to evaluate its worldwide trend by checking the amount of agricultural tractors, which grew by about 2.5 times from 1961 [10], and the increase in average power for each tractor. The needs of fuel for cultivation, considering both the number of tractors and their power increase, are taken from [11] and shown in fig. 1, considering the yield for each culture given in [12].

Applying these data to the average diet of pigs, bovines (beef is considered, not veal) and poultry, allows to obtain the energy cost for feed production; pesticides and fertilizers energy consumption is considered only for the main products, corn and wheat, while barley data are adjusted from wheat. Most of the products needed for feed production have to be transported from farm to feed factories: cereals, sunflowers and rapeseed are cultivated in Europe, soy comes from America (both North and South) [13,14]. They have to be prepared and then moved to breeding farms [13,14], with additional energy use. For transportation, the Italian feed supply chain is considered. 


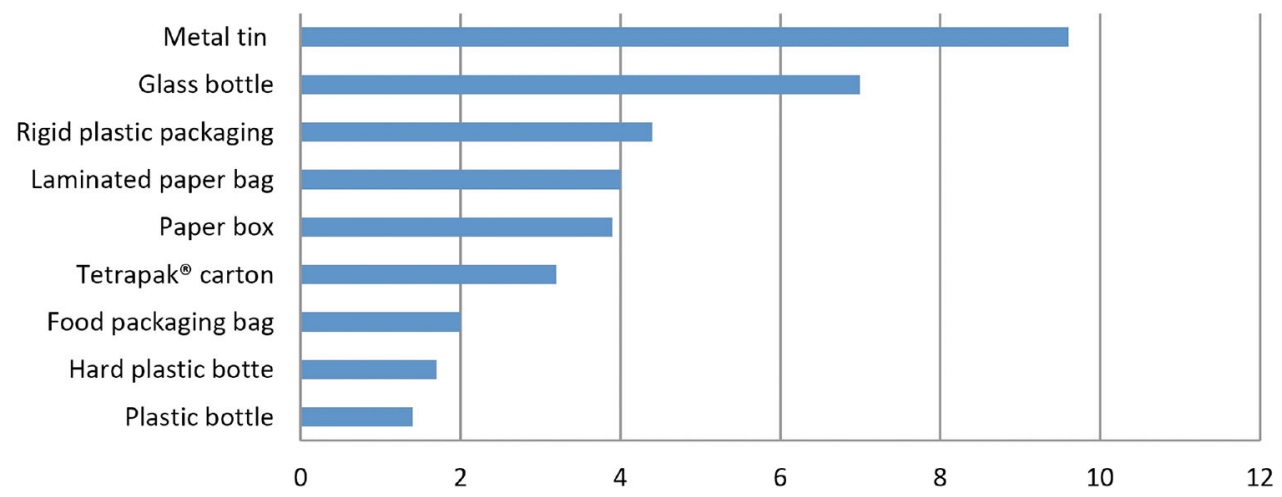

Fig. 2. Energy consumption $[\mathrm{MJ}]$ to produce $1 \mathrm{~L}$ volume food container, except for rigid plastic packaging, which is $1 \mathrm{~kg}$ packaging. Adapted from $[6,15,16]$.

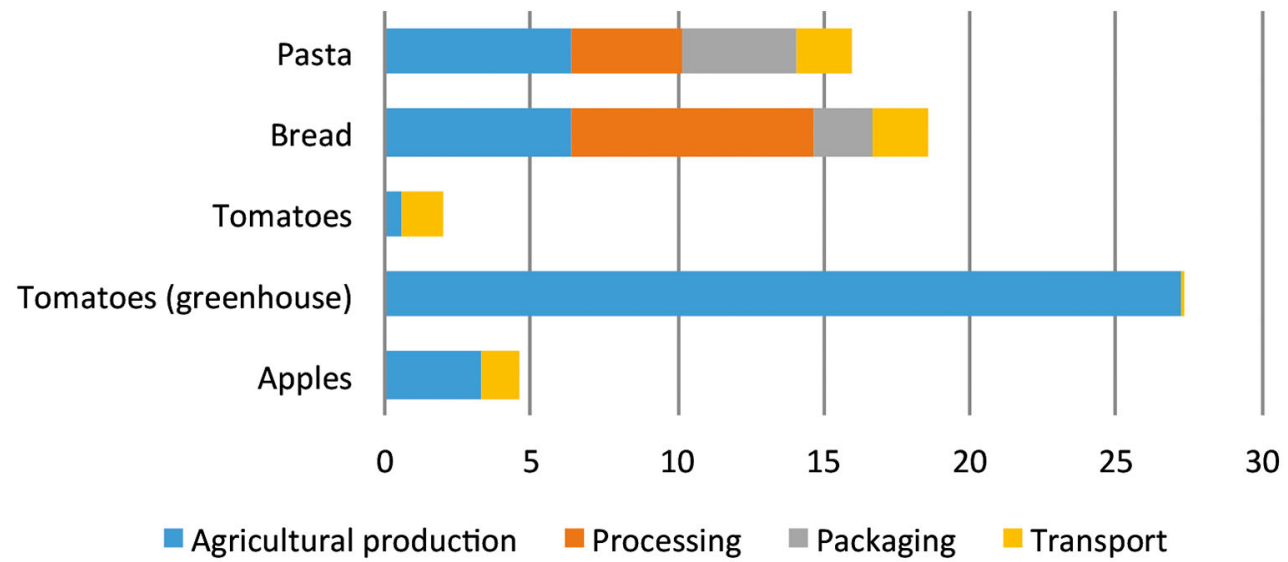

Fig. 3. Energy consumption per $1 \mathrm{~kg}$ of product $[\mathrm{MJ} / \mathrm{kg}]$, with a subdivision of the energy inputs in the food processing chain. Adapted from [2-8].

\subsection{Food transformations and transportation}

Processing is considered in terms of product conservation, since it is an important factor especially for foods that have a short life span. Energy consumption strongly varies depending on the kind of process [6]: solar drying does not need any energy input, whereas smoking or freeze-drying have the highest energy costs. Energy costs for final meat processing before the retail distribution can be calculated from [15].

Packaging is one of the methods used to help preserving food. We consider the energy inputs for different materials and packages, as shown in fig. 2. Considering beans production, the energy needed for the final product depends very much on the chosen package: the energy needed for $400 \mathrm{gr}(360 \mathrm{ml})$ of canned beans is $5.7 \mathrm{MJ}$ where $3.8 \mathrm{MJ}, 67 \%$ of the total energy, are used for the metal tin production [15]. If a Tetrapak® package is used instead of the metal tin, the energy cost for packaging is $1.2 \mathrm{MJ}$ on a total of $3.1 \mathrm{MJ}[15,16]$.

Transportation. During the last century there have been important changes in transportation; globalization, better food preserving and higher vehicle efficiency, have greatly increased the number and length of trading routes. Food can now be brought almost anywhere in the world; countries that cannot grow a certain kind of food in their territory (or just in a specific season) can still get it. The main factors affecting energy consumption in transportation are the length of trading routes, the type of marketing (supermarket, market, grocery store), the mean of transportation (train, plane, truck, barge), the product weight and its life span. There are several means of transportation, each requiring its own energy cost: truck, train and barge need a lot less energy than plane.

Figure 3 summarizes the energy costs of pasta, white bread, tomatoes and apples considering $2000 \mathrm{~km}$ transportation by truck; it is also presented the distribution of energy costs for greenhouse tomatoes with local origin (100 kilometers) based on energy inputs discussed before $[2,6,7,14-16]$. It is shown that the greatest energy cost for fresh products such as non-local tomatoes and apples comes from transportation; for local tomatoes out of season, grown in heated greenhouses, the energy cost of agricultural production is by far the greatest consumption, even higher than the energy required for processed and packed products.

The example of greenhouse-grown tomatoes shows that the energy savings coming from short transportation do not compensate for the high energy input required by the greenhouse heating. In general, fresh products need less energy than processed, packed or greenhouse-grown products. 


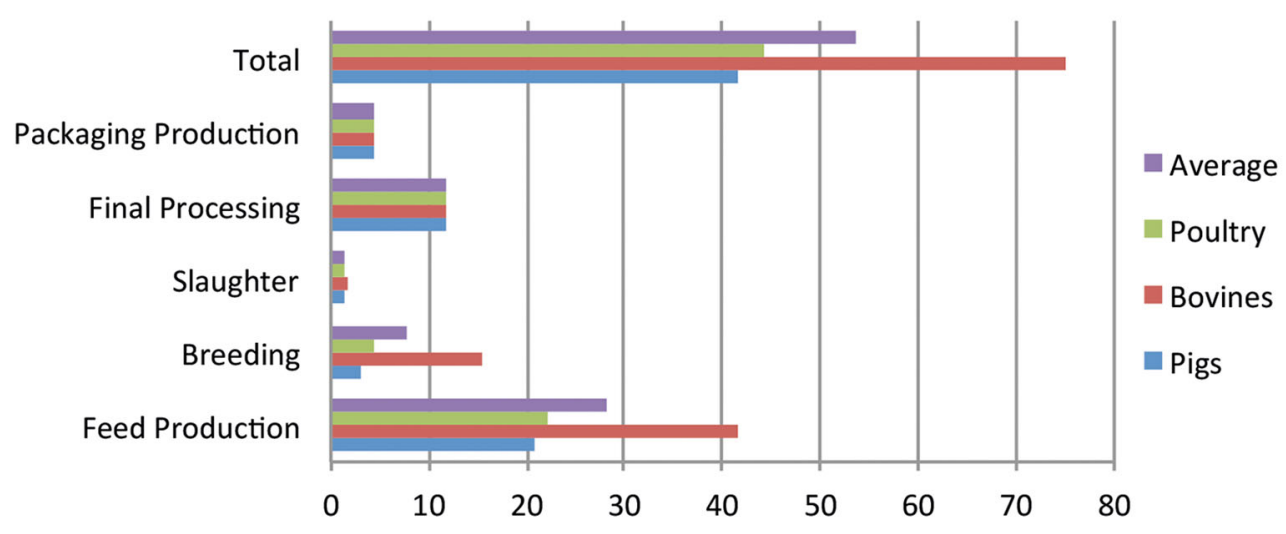

Fig. 4. Energy consumption in meat supply chain (MJ/kg of purchasable meat).

\subsection{Meet supply chain}

Energy data on breeding farms (heating, ventilation, distribution of food and water, lighting, effluent collection and treatment, cleaning and all the others mechanized activities useful to breeding management) can be obtained from [17-19]; since no information were found about energy consumption by breeding farms that produce bovine meat, information about dairy farming has been used, excluding the consumption due to the dairy processes (milking and milk cooling). Animals are moved from reproduction farms to breeding farms: data from the Italian situation are considered to calculate the energy needed for transportation. Bovines arrive from France (where they are born) to Italy (800 kilometers); pigs reproduction farms are in Italy, so an average distance of 100 kilometers can be considered; the energy needed for chicks transportation is negligible due to the high number of transported animals and the large weight increase. Animals are then moved from breeding farms to slaughterhouse and considering an average value of 150 kilometers, the total transportation energy can be evaluated [14]. Finally, data on energy consumption in slaughterhouses are taken from [17].

Figure 4 summarizes the meat supply chain data: the highest energy cost is for the bovine meat production $(75 \mathrm{MJ} / \mathrm{kg}$ ): this mainly comes from the lowest bovine final yield (weight of purchasable meat compared to total weight of the animal) compared to pigs or poultry $(44 \%, 72 \%$ and $63 \%)$.

Figure 4 also shows that feeding always has the highest component requiring at least $50 \%$ of the energy required by the whole production chain; feeding is followed by final processing for pigs and poultry and by breeding for bovines. Slaughter needs few energy if compared with other processes and transports (raw materials, feed and animals) influence the total amount of energy needed by $8 \%$ for pigs and for bovine and $10 \%$ for poultry.

\subsection{Energy gain}

Summarizing the data presented up to now, the ratio $G$ between energy output over energy input can be calculated, thus showing the difference between different kinds of production. This is clearly visible in the case of tomatoes: when tomatoes are grown conventionally, $G$ is a little bit over one (there is a little gain in the energy output); when tomatoes are coming from $2000 \mathrm{~km}$ away $G=0.43$, but when tomatoes are cultivated in heated greenhouses $G=0.03$. Considering also the energy costs after the agricultural production stage, the $G$ value gets a further reduction, as it does for wheat: considering only the agricultural production $G=2.24$ but, evaluating the total energy consumption, for white bread and pasta $G=0.65$ and $G=0.94$ respectively. The $G$ value also shows differences between crops: cereals, as already shown for wheat, having a high energy content and requiring not much energy per hectare, have a $G$ value over one (e.g., oats $G=5.11$, maize $G=3.12$, rice $G=2.23$ ). The $G$ value for fruits is close to one (e.g., oranges $G=1.03$, apples $G=0.71$ ), requiring great quantity of energy balanced by the high production yield; the same is true for vegetables, as already shown for tomatoes and tubers (e.g., potatoes $G=1.33$ ).

The same calculation can be done for meat production: in general, inserting one more step in the food production chain, that is one more energy transformation, a lower $G$ value is expected compared to the original animal feed $G$ value. Considering the energy provided by $1 \mathrm{~kg}$ of swine, bovine or poultry meat, respectively, 9.8 MJ, $10.7 \mathrm{MJ}$ and $5.7 \mathrm{MJ}[8]$, and comparing it to the energy input needed in the supply chain, the $G$ value is 0.24 for pork, 0.14 for beef and 0.13 for poultry.

\section{Energy losses in the food production chain}

Every energy transformation leads to some energy loss: as seen, food production does not make an exception. 
We define energy loss as the difference between chemical-energy content of what the consumer actually eats and whatever energy input aimed to produce it. Thus, we shall not consider packaging, transportation and processing, which could be more properly defined as energy costs.

Even if different ways to cook the same food could lead to different chemical-energy contents, for the sake of simplicity we shall not consider this aspect in our definition of energy loss.

It is recognized [20] that around $32 \%$ of the losses is due to agricultural sector, $22 \%$ is due to post-harvest phase, $13 \%$ to distribution, $11 \%$ to industrial manufacturing and the remaining $22 \%$ happens in houses.

The main path to save energy in agricultural and livestock sectors is to produce organic fertilizers. According to FAO estimates [21], organic fertilizers constitute no more than $15 \%$ of all fertilizer used in developed countries; in developing countries, this share is probably higher, but there are not precise data to quote.

The principal cause of energy loss in agriculture and livestock sectors is the low efficiency of both plants in producing fruits or seeds and of cattle metabolism. Plants devolve 5-50\% of their stored energy to produce fruits and seeds [22]; this means that most of the energy is used to create non-edible parts of the plant, that are therefore, from our point of view, energy losses. How much energy is lost depends on the specific plant. The issue of quantifying and reusing energy from discarded biomass will be developed in the next sect.

Efficiency in cattle metabolism is much lower than the one of plants: it is quite common to consider that the conversion from biomass used to feed an animal to the animal biomass rates on average 10:1. This means that we lose much more energy with cattle than we lose with plants and agriculture; however, this also means that we can hope to have bigger energy savings from livestock.

Energy lost by cattle is mainly thermal energy and discarded biomass (excrements): while thermal energy is quite difficult to save, energy of discarded biomass is widely used. The energy content of discarded biomass is mainly composed of a huge share of chemical energy and a tiny part of thermal energy. Before discussing the chemical part, it is interesting to give an estimate of thermal energy, in order to underline how significant even a small entry in the energy balance of food production may be.

Let us consider $1 \mathrm{~kg}$ of excrements (i.e. one third of the daily discarded production of a single cow) cooling down from internal cow temperature, $39^{\circ} \mathrm{C}$, to the average annual temperature in the Po Valley, around $14^{\circ} \mathrm{C}$. Taking a reasonable value for the specific heat from a work by Nayyeri et al. [23] with some extrapolation, $2 \mathrm{~kJ} / \mathrm{kg} /{ }^{\circ} \mathrm{C}$, the result is $48 \mathrm{~kJ}$ : such an energy would be enough to lift a weight of $80 \mathrm{~kg}$ up to a height of $60 \mathrm{~m}$. Moreover, if we repeated the calculation for the average daily urine production of the average cow, we would find a total discarded-biomass thermal loss of 1.5 MJ per cow, every day.

This portion of energy, as we said before, has a minor role with respect to the chemical share and it is clear that this thermal energy cannot be easily saved but as natural heating of the stable where cows are bred.

It is quite difficult to make a correct estimate of the total chemical energy density of animal excrements: for instance, it is not obvious if binding-energy of nitrogen-compounded molecules has to be taken into account. Plants can absorb nitrogen both from organic and from chemical fertilizers: the more nitrogen-compounded molecules are present in manure, the lesser fossil energy is needed for the chemical synthesis of fertilizers (0.7 TOE of energy is needed for 1 tonne of fertilizer [24]). Moreover, it is not clear whether the energy contained in fibres has to be taken completely into account: excrements undergo a process of exothermal simplification of fibres into simpler starches and methane before being used as manure. A good compromise could be defining the bare energy density as the energy produced by direct combustion of dry matter, which is about $10 \mathrm{MJ} / \mathrm{kg}$.

There are two main methods to recover energy from cattle excrements: manure and methane production. Not every technique is good in order to produce both of them: in particular, all traditional techniques are bound to lose almost all the gaseous fraction.

Eventually, an interesting way to handle both animals' excrements and losses from industry, market and houses is bio-digestion, which creates a favourable environment for bacteria, accelerating, thus, decomposition and stabilization.

In fact, there are two kinds of bioreactors, depending on the kind of digestion they tend to reproduce: aerobic and anaerobic ones. Actually, the latter is also a valid compromise between manure and methane production [25].

Saving food is another way to save energy: based on FAO estimates, every year in the world $1.6 \mathrm{Gt}$ of food are wasted and $80 \%$ of these losses are still edible; they represent one third of the world yearly production. A way to prevent food from being wasted is to donate it to food-banks. Unfortunately, it is quite difficult to quantify precisely how much food can actually be saved in this way, because there is no database gathering the information of a huge number of food-banks spread all around the world. Nevertheless, we can have an idea considering data from Global FoodBanking Network (GFN), which are relative to food-banks from USA, UK, Japan, Singapore, Egypt and many other African countries (no EU country besides UK, few Asian ones and none from Oceania and South America). GFN declares to save every year 540000 tonnes of edible food: just about $0.04 \%$ of the edible food waste declared by FAO.

Eventually, energy savings in food production can be summarized in two categories:

1) when energy has already the shape of food (mainly through food donations)

2) when energy still has some other shape. 
Table 1. World residue calculated on eq. (2) with HI from [26]. HV indicates the higher calorific value of the considered cereal. "MC" stands for "multiplicative coefficient" and indicates the ratio between tonne residue and tonne cereal.

\begin{tabular}{|l|c|c|c|c|c|}
\hline Crop & $\begin{array}{c}\text { Residue } \\
\text { [Mton] }\end{array}$ & MC & $\begin{array}{c}\text { \% Residue } \\
{[\text { Mton] }}\end{array}$ & $\begin{array}{c}\mathrm{HV} \\
{[\mathrm{MJ} / \mathrm{kg}]}\end{array}$ & $\begin{array}{c}\text { Energy } \\
{[\mathrm{EJ}]}\end{array}$ \\
\hline Cereals & 1774.2 & 0.22 & 390.3 & 17.5 & 6.8 \\
Wheat & 491.1 & 0.22 & 108.0 & 17.5 & 1.9 \\
Barley & 115.1 & 0.22 & 25.3 & 17.5 & 0.4 \\
Maize & 448.3 & 0.25 & 112.1 & 16.8 & 1.9 \\
Rice & 494.0 & 0.22 & 108.7 & 17 & 1.9 \\
\hline
\end{tabular}

Globally, as we have seen, the first category saves very little energy, while the second one is a much more relevant energy saving process. Nevertheless, the first category may look more relevant on a human dimension, because donating food to people is ethically quite different from recycling garbage. Overall, the two of them represent a minor quantity when compared both to total energy losses and to total energy inputs (at least in developed countries). However, in this particular production chain, energy is strongly bound to life dignity of human beings and thus even small energy savings assume greater importance.

\section{Energy from cereal residue}

Biomass is organic matter derived from living or recently living organism. Biomass for energy includes a wide range of materials: virgin wood, agricultural residues, energy crops, food waste, and industrial waste. Bioenergy is energy derived from the conversion of biomass and it is the largest renewable energy source: currently, it accounts for roughly $10 \%$ of the world total primary energy supply. In 2013, 462 TWh of electricity from bioenergy have been produced and this corresponds roughly to $2 \%$ of the world electricity generation [27]. In order to minimize green house gas emissions, countries are looking for alternative sources of energy. Bioenergy reduces dependency on the fossil fuel consumption, contributing to energy security and climate change mitigation.

Agricultural activities generate large amounts of biomass residues coming from all those parts of the plant that are not addressed for primary use: in general these are support and protection structures for plants. The evaluation of agricultural residues availability is difficult because of the important differences among various crops. Data on a specific crop production depend on climatic condition, land fertility, productivity of the system and technology that has been used. The amount of residues also depends on terrain yield. The energy extracted from agricultural residues may be significant but alternative use must also be considered.

The ratio of crop seeds over the total biomass produced is called harvest index and this changes during the years. Harvest index describes plant ability to allocate biomass into reproductive parts; hence it is an important characteristic for plant breeding [28]:

$$
\begin{aligned}
\mathrm{HI} & =\text { production } /(\text { biomass yield }), \\
\text { Residue } & =\text { biomass yield }- \text { production } .
\end{aligned}
$$

Crop residues in this study include straw from wheat, barley and rice and corn stover (stalks and cobs) from maize. Harvest indices are assumed according to [26]. As a general rule, in order to ensure long-term productivity, only part of the residues should be harvested to avoid depletion of organic matter in the soil [28, 29]: only about 0.22 tonne straw per tonne cereal, with the exception of maize (table 1), are available for energy use [29].

As shown in table 1, the energy that could be obtained from residue of major cereals (wheat, barley, maize and rice) is 6.1 EJ. Considering the amount of all cereals, $6.8 \mathrm{EJ}$ could be produced which represent roughly $1.2 \%$ of the world primary energy demand in 2013 [10].

Energy recovery from residual agricultural biomass has a potential that developed countries are interested in exploiting. Many studies have reached different conclusions about future contribution of biomass to global energy supply: the major reason for these differences is that land availability and yield levels in energy crop production, the most crucial parameters, are very uncertain and subject to widely different opinions. Agricultural residues are a mean to avoid conflicts between human food use and industrial use of crops.

According to the International Renewable Energy Agency 2014 report [30], bioenergy could reach 108 EJ worldwide by 2030: it could account for $20 \%$ of total primary energy supply and $60 \%$ of final renewable energy use. The way we use biomass can be expected to change in the next few years: at present, two-thirds of total biomass use, accounting for $35 \mathrm{EJ}$, are for cooking, heating and burning firewood. By 2030, power and district heating could reach 36 EJ (one-third of total biomass use in 2030), transportation 31 EJ (almost 29\%), while heat for industry and buildings could go up to 41 EJ. Global biomass supply potential in 2030 is estimated to range from 97 EJ to 147 EJ per year. About $40 \%$ of this amount would originate from agricultural residues and waste (37-66 EJ). The remaining supply potential is shared between energy crops (33-39 EJ) and forest products, including forest residues (24-43 EJ). 


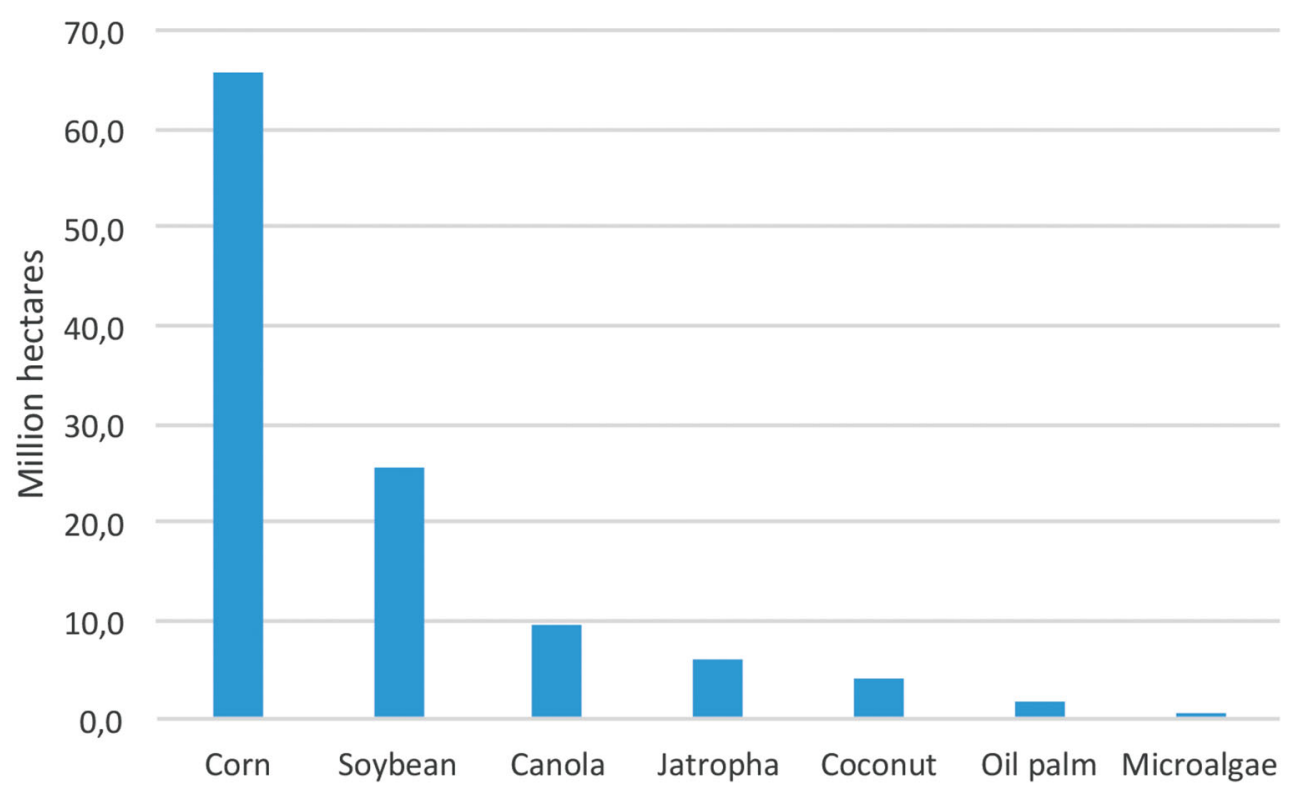

Fig. 5. Area needed to meet $1 \%$ of the total annual US fuel needs (1.13 billion $\mathrm{m}^{3} /$ year) with biodiesel [31]. The estimate does not include the energy production consumption. The algae area is about 200000 ha: algae would need roughly $10^{7}$ ha to meet the entire US fuel demand.

\section{Algae for biofuel production}

Algae is a generic term for a group of eukaryotic organisms that possess chlorophyll as photosynthetic pigment and do not present a real differentiation of tissues (like leaves and roots). Among algae there are single-cell organisms, such as Chlorella, and multicellular forms such as Kelp, which can be 50 meters long. Most of these species are aquatic and can live in fresh water (e.g., Charophyta) or salt water (e.g., Rhodophytes). Typically, they are autotrophic organisms that produce chemical energy by photosynthesis. However some species can be mixotrophic or heterotrophic (without photosynthetic apparatus). Algae include about 72500 species [32], but it is estimated there could be many more. Their photosynthetic activity is important: they are responsible for $50 \%$ of the oxygen produced on Earth [33].

Like land plants, some species of algae accumulate the products of photosynthesis as polysaccharide chains (e.g., Chlorella, or Spirogyra), and some store energy in lipid chains (e.g., Dunaliella sp.). Some algae species, however, can reach higher sugar and lipid concentration compared to land plants: in particular, sugar concentration can be $50 \%$ of the dry algal cell [34], while land plants do not exceed 20\% (sugar beet).

The main features that differentiate algae from land plants in the biomass production are:

1) Algae evolved to carry out photosynthesis with water-filtered light: this made them particularly efficient in the use of solar energy. Since they do not present a real differentiation of tissues, the energy obtained by photosynthesis is not used for the construction of complex structures, and can be directly accumulated.

2) Their surface is totally photosynthetic [35]. Land plants, in contrast, concentrate the photosynthetic pigment in small percentages of the total area (generally in leaves). This enables algae, under right conditions, to rapidly produce a large amount of biomass.

3) Algae evolution occurred in a floating state. This means they do not have lignin, a complex structure indigestible by the bacteria used during the fermentation, key step for the industrial production of ethanol.

Algae show interesting properties in terms of solar efficiency conversion to biomass. For traditional terrestrial crops, the theoretical maximum is around $4.6 \%$ for $\mathrm{C} 3$ and $6 \%$ for $\mathrm{C} 4$ plants [36]. For algae, estimates of theoretical upper limits of photosynthetic efficiency have not been conducted yet, but microalgae may have a lower respiratory rate that would raise this parameter. Moreover, the smaller photosystem antenna size would prevent photons over-absorption by individual cells, enabling deeper sunlight-penetration into the culture, and affording an opportunity for more cells to be productive [37].

Large-scale algae production would have several advantages compared to a terrestrial crop.

Growth speed. Algae have life cycles of the order of hours or days. Land plants generally take months, or years, to make a comparable production of biomass. This is very important, since growth speed increases productivity and savings of resources.

Agriculture competition. Currently, traditional crops like sugar cane, wheat and soybeans dominate biofuel production. Such a biofuel production from terrestrial biomass is not sustainable in the long term: consider that using corn, an half of the whole arable U.S. land would be necessary to meet only about $1 \%$ of the annual internal fuel demand [31] with biodiesel (see fig. 5). Furthermore, this would be to the detriment of crops for food uses. According 
to a recent estimate, the world food demand will grow by $70 \%$ by 2050 [38]. Algae represent an interesting solution to this problem, because they do not require arable land to grow: they can grow in bioreactors, tanks, and in the sea too. Moreover, their development does not require pesticides, preventing water and soil contamination, and fertilization is limited to tubs or bioreactors, their living environment.

No pure water need. Agriculture is responsible for $70 \%$ of world water usage [38]. Algal crops would be a positive response to this problem too, because they can grow in wastewater, seawater and brackish water. Indeed, wastewater can constitute a mix of nutrients suitable for different types of algae, which can accumulate heavy metals, pesticides, organic and inorganic toxic and radioactive substances in cells [39]. This makes algae effective in the purification of wastewater.

A few words about the promising use of algae for food production. Seaweeds are traditional sources of nutrition, especially in asian countries. In Europe, algae are mainly used for the production of additives or meal for animal nutrition. The nutritional value of algae depends on the considered species. However, protein is always the major organic constituent, followed usually by lipid and then carbohydrate: expressed as percentage of dry weight, they are $12-35 \%, 7.2-23 \%$, and 4.6-23\%, respectively [40]. Seaweeds (especially the Chlorophyceae and the Rhodophyceae) could be a complementary source of food proteins for human nutrition, since their amino acid composition is very differentiated among the existing species [41]. The use of high level protein seaweeds in feed for fish farming, in particular, seems to be a promising way for the utilization of this plant marine resource [40,41]. The co-production of a high value-added products would be economically beneficial to an algae-based system for production of biodiesel (e.g., spent algal biomass can be sold as animal feed) [34].

\section{Conclusions}

Energy is essential in nowadays life for any activity we perform. Throughout this paper some aspects concerning energy use and production related to the food chain have been presented: energy consumption evaluation for the production of various types of foods, the potential of energy recovery from agricultural and livestock residues with reference to energy crops, the potential of algae for the production of biofuels. The paper also has a focus on food energy balance comparing the energy needed to produce, transform and transport few selected foods to the final user, with the energy content of the same products. Nevertheless, we are aware that this is a limited point of view: other nutritional values of food, e.g. protein content, could be taken into account to analyze the issue of the food quality when considering the energetic cost of different kind of foods. This may be the subject for a future new task.

We thank EnergyLab Foundation in Milan for offering us the chance to study this subject and for supporting us in presenting our job to EXPO 2015.

\section{References}

1. V. Smil, Energy in the World History (Westview Press, Boulder, 1994).

2. D. Pimentel, Energies 2, 1 (2009).

3. C.W. Gellings, K.E. Parmenter, Efficient use and conservation of energy, Vol. II, Energy Efficiency in Fertilizer Production and Use (UNESCO-EOLSS, 2004) pp. 123-136.

4. M.B. Green, Energy in pesticide manufacture, distribution, and use, Energy in Plant Nutrition and Pest Control. Energy in World Agriculture, Vol. 2 (Elsevier, 1987) pp. 165-177.

5. Z.R. Helsel, Energy in pesticide production and use, in Encyclopedia of Pest Management (Taylor \& Francis, London, 2006).

6. D. Pimentel, M.H. Pimentel, Food, Energy, and Society, 3rd edition (CRC Press, 2008) chapt. 17.

7. A. Van Hauwermeiren et al., J. Environ. Policy Plan. 9, 31 (2007).

8. D. Pimentel, M.H. Pimentel, Food, Energy, and Society, 3rd edition (CRC Press, 2008) chapt. 8.

9. J.C. Steinhart, Science 184, 307 (1974).

10. FAOSTAT, http://faostat3.fao.org/.

11. ENAMA (Ente Nazionale per la Meccanizzazione agricola), Prontuario dei consumi di carburante per l'impiego agevolato in agricoltura (2005).

12. Agraria.org, http://www.agraria.org (2012).

13. D. Cevolani s.r.l., Panorama del mercato mangimistico e della nutrizione animale in Italia (2012).

14. http://www. ecotransit.org/calculation.it.html.

15. Environmental Product Declaration of Coop Beef Meat, Barilla Dry Semolina pasta from durum wheat, Mulino Bianco bakery products, Ferrarelle mineral water, Zefiro refined sugar from sugar beet, Granarolo High Quality milk, http://www. environdec.com (2016).

16. Life Cycle Inventory of Container Systems for Wine, Tetrapak®, http://www.tetrapak.com/sustainability/ managing-our-impact/climate-impact/life-cycle-assessments (2007). 
17. IPPC (Integrated Pollution Prevention and Control), guidelines for Best Available Techniques modelling in livestock, ISPRA (2005), http://www.isprambiente.gov.it/contentfiles/00008100/8186-lg-mtd-allevamenti-12settembre2005.pdf.

18. CRPA (Centro ricerche produzioni animali), Progetto per lo sviluppo delle diverse tecnologie per il risparmio energetico e per lo sfruttamento di energia solare negli allevamenti dell'Emilia-Romagna (2011).

19. Table of conversion of animals livestock units, Commission Regulation (EC) No 1974/2006, laying down detailed rules for the application of Council Regulation (EC) No 1698/2005 on support for rural development by the EAFRD.

20. A. Segré, M. Pessato, Waste Watcher - Knowledge for Expo (2014).

21. FAO, World Livestock 2011 - Livestock in Food Security (Rome, FA, 2011).

22. D. Pimentel, M.H. Pimentel, Food, Energy and Society, 3rd edition (CRC Press, 2008).

23. M.A. Nayyeri et al., Int. Agrophys. 23, 359 (2009).

24. Yara International, Nitrogen Fertilizer Brochure (2011).

25. SAIC, Aerobic and Anaerobic Bioreactor Project Protocol (2011) chapt. 3.

26. S. Wirsenius, Human Use of Land and Organic Materials: Modelling the Turnover of Biomass in the Global Food System (Chalmers University of Technology and Goteborg University, 2000).

27. IEA, Heating without global warming (2014).

28. A. Wnuk, G. Górny, J. Bocianowski, M. Kozak, Commun. Biometry Crop Sci. 8, 48 (2014).

29. K. Ericsson, L.J. Nilsson, Biomass Bioenergy 30, 1 (2006).

30. IRENA, Global Bioenergy Supply and Demand Projections for the year 2030 (2014).

31. Y. Chisti, Biotechnol. Adv. 25, 294 (2007).

32. M.D. Guiry, J. Phycol. 48, 1057 (2012).

33. C.B. Field, M.J. Behrenfeld, J.T. Randerson, P. Falkowski, Science 281, 237 (1998).

34. C. Formighieri, Solar-to-Fuel Conversion in Algae and Cyanobacteria (Springer, 2015).

35. C. Formighieri, R. Bassi, Algae as a "New" Biomass Resource - Possibilities and Constraints, Encyclopedia of Sustainability Science and Technology (ESST) (Springer, New York, 2012).

36. X. Zhu, S.P. Long, D.R. Ort, Curr. Opin. Biotechnol. 19, 153 (2008).

37. D.R. Ort, X. Zhu, A. Melis, Plant Physiol. 155, 79 (2011).

38. E. Stephens, I.L. Ross, B. Hankamer, Curr. Opin. Chem. Biol. 17, 444 (2013).

39. S. Bulent, T. Mehmet, S. Feray, A. Mehmet, C. Ozur, Water Treatment (InTech, 2013).

40. Manual on the Production and Use of Live Food for Aquaculture FAO fisheries technical paper, Rome (1996).

41. J. Fleurence, Trends Food Sci. Technol. 10, 25 (1999) 